Published in final edited form as:

Curr Opin Physiol. 2019 June ; 9: 26-33. doi:10.1016/j.cophys.2019.04.022.

\title{
Redox Signaling in Sickle Cell Disease
}

Deirdre Nolfi-Donegan ${ }^{1}$, Tirthadipa Pradhan-Sundd ${ }^{2}$, Kirkwood A. Pritchard Jr. ${ }^{3}$, and Cheryl A. Hillery ${ }^{1}$

${ }^{1}$ Department of Pediatrics, Division of Pediatric Hematology/Oncology, University of Pittsburgh School of Medicine, Pittsburgh, PA, United States

${ }^{2}$ Department of Pathology, University of Pittsburgh School of Medicine, Pittsburgh, PA, United States

${ }^{3}$ Department of Surgery, Division of Pediatric Surgery, Medical College of Wisconsin, Milwaukee, Wisconsin, United States

\section{Abstract}

Sickle cell disease (SCD) is characterized by chronic hemolysis and repeated episodes of vascular occlusion leading to progressive organ injury. SCD is characterized by unbalanced, simultaneous pro-oxidant and anti-oxidant processes at the molecular, cellular and tissue levels, with the majority of reactions tipped in favor of pro-oxidant pathways. In this brief review we discuss new findings regarding how oxidized hemin, hemolysis, mitochondrial dysfunction and the innate immune system generate oxidative stress while hemopexin, haptoglobin, heme oxygenase-1 (HO-1) and nuclear factor erythroid 2-related factor 2 (Nrf2) may provide protection in human and murine SCD. We will also describe recent clinical trials showing beneficial effects of antioxidant therapy in SCD.

\section{Keywords}

sickle cell disease; hemoglobin; oxidative stress; hemolysis; inflammation

\section{Introduction}

Sickle cell disease (SCD) is caused by a single point mutation in the hemoglobin beta chain that predisposes sickle hemoglobin ( $\mathrm{HbS}$ ) to polymerize upon deoxygenation, forming crystals that distort and injure the red blood cell (RBC) membrane (1). Consequently, fragile sickle RBCs are prone to lysis, releasing hemoglobin and other RBC cellular components into the circulation. This leads to endothelial oxidative injury, inflammation and increased adhesion of leukocytes, RBCs and platelets that results in repeated episodes of

Corresponding Author: Cheryl A. Hillery, M.D., Division of Pediatric Hematology/Oncology, University of Pittsburgh School of Medicine, 4401 Penn Avenue, Pittsburgh, PA 15224, Phone: 412-692-6211, Fax: 412-692-6211, cheryl.hillery@ chp.edu.

Publisher's Disclaimer: This is a PDF file of an unedited manuscript that has been accepted for publication. As a service to our customers we are providing this early version of the manuscript. The manuscript will undergo copyediting, typesetting, and review of the resulting proof before it is published in its final citable form. Please note that during the production process errors may be discovered which could affect the content, and all legal disclaimers that apply to the journal pertain. 
microvascular stasis ("vaso-occlusion"), tissue ischemia and cumulative organ damage (2). Many features of SCD vaso-occlusion resemble the ischemia-reperfusion injury and vascular inflammation described in cardiovascular disease. Despite the many pathways by which oxidative stress exacerbates pathologies in SCD, there are few therapeutic interventions proven to be effective in reducing the pro-oxidant environment of SCD (Figures 1 and 2).

\section{Hemoglobin, Heme and Hemin}

Hemoglobin is comprised of 2 alpha globin chains, 2 beta globin chains and a heme cofactor that contains ferrous iron $\left(\mathrm{Fe}^{2+}\right)$; oxidation of iron to the ferric $\left(\mathrm{Fe}^{3+}\right)$ state results in methemoglobin. The heme cofactor is tightly bound to the globin proteins when iron is in the ferrous/oxy state; upon oxidation to the ferric form (hemin), methemoglobin is formed and the hemin cofactor is readily released from the protein. While the terms "heme" and "hemin" are frequently interchanged, in this review we refer to heme that is oxidized $\left(\mathrm{Fe}^{3+}\right)$ as hemin.

\section{Sickle RBC, microparticles and hemolysis}

$\mathrm{HbS}$ readily auto-oxidizes to form methemoglobin, hemin, and superoxide within the RBC. This impacts many cellular activities, including cytoskeletal oxidation, membrane lipid peroxidation and phosphatidylserine exposure, all culminating in decreased RBC deformability and premature cell death. Without mitochondria, RBCs rely on glycolysis for energy and produce NADH (nicotinamide adenine dinucleotide (NAD) + hydrogen (H)) that is a key antioxidant, reducing metHbS to its less dangerous ferrous state. Unfortunately nicotinamide adenine dinucleotide phosphate (NADPH) oxidase is upregulated in sickle RBCs and depletes NADH. Glutathione, a scavenger of reactive oxygen species (ROS), is also depleted within sickle RBCs, further contributing to sickle RBC oxidative stress (3).

Repeated HbS polymerization ("sickling") and RBC oxidative injury promote shedding of RBC microparticles (4). Sickle RBC-derived microparticles induce ROS in cultured endothelial cell and acute vaso-occlusion in sickle mouse kidneys (5). Heme bound to externalized microparticle phosphatidylserine may drive this biologic effect $(4,6)$. Sickle microparticles formed by shearing RBCs through a small gauge needle formed high levels of oxidized ferric and ferryl hemoglobin compared to control microparticles $\left(7^{*}\right)$. Furthermore, protein carbonylation and lipid hydroperoxides increased while antioxidants dropped in sickle microparticles compared to minimal changes observed in healthy RBC microparticles. Interestingly, shear-generated or native circulating sickle microparticles, but not control microparticles, formed oxidized $\beta$ Cys 93 and, unexpectedly, ubiquitination of $\beta$ Lys 96 and $\beta$ Lysl45 in sickle microparticle $\beta$ globin, suggesting a novel link between oxidative stress and the ubiquitin pathways (7).

Chronic intravascular hemolysis releases a constant supply of cell-free hemoglobin and heme/hemin that exerts pro-oxidant effects in the circulation (8). Oxyhemoglobin $\left(\mathrm{Fe}^{2+}\right)$ scavenges nitric oxide (NO) to form nitrate $\left(\mathrm{NO}_{3-}\right)$ and methemoglobin $\left(\mathrm{Fe}^{3+}\right)$, shunting $\mathrm{NO}$ away from endothelial cells and contributing to endothelial dysfunction (9). Release of arginase-1 from hemolyzed RBCs metabolizes 1-arginine, the building block for NO, further 
reduces NO bioavailability (10). Hemoglobin may also react with hydrogen peroxide $\left(\mathrm{H}_{2} \mathrm{O}_{2}\right)$ through the Fenton reaction to form hydroxyl free radical $(\mathrm{OH} \bullet)$ and methemoglobin. Methemoglobin can further degrade to hemin $\left(\mathrm{Fe}^{3+}\right)$, which is a major $\mathrm{RBC}$ damageassociated molecular pattern (DAMP). These hemolysis-associated ROS contribute to activation of inflammatory and adhesive pathways in endothelial cells, platelets and neutrophils that can lead to vaso-occlusion in SCD. In agreement, infusion of hemin directly induces acute vascular occlusion in sickle mouse lungs that is improved with inhibition of $\mathrm{P}$ selectin mediated adhesion pathways $(11 *)$.

\section{Protection against heme toxicity via haptoglobin, hemopexin and HO-1}

Haptoglobin and hemopexin protect against heme toxicity by binding and removing cell-free hemoglobin and hemin, respectively. Unfortunately, both scavengers are rapidly cleared in the setting of hemolysis (8). Using mouse dorsal skinfold chambers to assess microvascular flow, infusion of hemoglobin or hemin causes acute vascular stasis in sickle, but not control mice, while the co-administration of haptoglobin or hemopexin restored the microvascular blood flow to control levels (12). Correspondingly, genetic overexpression of hemopexin in sickle mice prevents microvascular occlusion, upregulates protective liver nuclear factor erythroid 2-related factor 2 (Nrf2) expression and heme oxygenase-1 (HO-1) activity, and decreases pro-inflammatory nuclear factor kappa-light-chain-enhancer of activated $\mathrm{B}$ cells (NF- $\mathrm{kB}$ ) activation in the face of hemin infusion. Conversely, sickle cell hemopexin knockout mice exposed to hemin experience worse venostasis (13).

HO-1 is an inducible enzyme that catabolizes heme to biliverdin, carbon monoxide and ferrous iron and has multiple additional cytoprotective effects. In sickle mice, a single infusion of haptoglobin or hemopexin increased HO-1 expression and decreased NF- $\mathrm{kB}$ activity in multiple tissues; the haptoglobin/hemopexin infusion also protected against vasoocclusion for up to 48 hours (14). The effect of HO-1 on NF- $\mathrm{kB}$ activity and venostasis was independent of plasma concentrations of hemoglobin or hemin, suggesting that the beneficial effects of haptoglobin and hemopexin are not wholly attributable to the clearance of hemoglobin and hemin from circulation (14). Administration of oral carbon monoxide to sickle mice increased Nrf2 and HO-1 expression while decreasing NF- $\mathrm{kB}$ activation, soluble vascular cell adhesion molecule-1 (VCAM-1), and venostasis (15*)

\section{Nrf2 antioxidant effects and fetal hemoglobin induction}

Nuclear factor erythroid 2-related factor 2 (Nrf2) is a basic leucine zipper transcription factor that protects cells from oxidative damage by promoting the expression of a wide variety of antioxidants (16-25). Kelch-like ECH-associated protein 1 (Keap1) regulates Nrf2 activity $(20,23,24)$. Under normal physiological conditions, Keap1 sequesters Nrf2, which is then ubiquitinated by cullin-3 containing ubiquitin ligase and degraded. Under physiological stress, the interaction between Nrf2 and Keap1 is inhibited by reactive oxygen species or toxic xenobiotics, resulting in constitutive activation of $\mathrm{Nrf2}(20,23,24)$. Nrf2 activation has been shown to have a protective role in oxidant mediated multi-organ injury associated with SCD by removing plasma heme caused by SCD induced hemolysis (16-19, 21, 25). Similarly, Nrf2 inducer CDDO-Im (2-cyano-3, 12 dioxooleana-1, 9 diene-28- 
imidazolide) also ameliorated inflammation and oxidative stress in liver and lung of SCD mice (16). Remarkably, in humans, Nrf2 gene silencing by miR-144 inhibited fetal hemoglobin $(\mathrm{HbF})$ expression, which is used to reduce the disease severity of SCD. Blocking miR-144 reversed the silencing effect of Nrf2 (22*). In KU812 cells, hemininduced oxidative stress (which triggers inflammation in SCD) also caused Nrf2 activation and $\mathrm{HbF}$ induction which was inhibited by miR-144 treatment (22). Chromatin immunoprecipitation assay, genome-wide miRNA microarray and primary erythroid progenitor data confirmed the binding of Nrf2 with $\gamma$-globin antioxidant response element, which is responsible for $\mathrm{HbF}$ production, and established its protective role in SCD regulation (22).

\section{Mitochondrial dysfunction and oxidative stress in SCD platelets}

Oxidative stress likely contributes to increased platelet activation observed in SCD and activated platelets are tightly integrated within the acute vaso-occlusive process $\left(26^{*}, 27\right)$. Compared to healthy controls, sickle platelets have decreased mitochondrial respiration, increased mitochondrial membrane potentials and produce higher levels of the mitochondrial oxidant product, $\mathrm{H}_{2} \mathrm{O}_{2}$. The degree of mitochondrial hyperpolarization or $\mathrm{H}_{2} \mathrm{O}_{2}$ production correlates with the level of increased sickle platelet activation, which points toward mitochondrial complex $\mathrm{V}$ dysfunction. The degree of reduced complex $\mathrm{V}$ activity in sickle platelets correlates with measures of hemolytic rate, including the level of cell-free hemoglobin. Interestingly, treatment of healthy platelets with hemoglobin reduces complex $\mathrm{V}$ activity and mitochondrial oxygen consumption rates, while increasing mitochondrial membrane potential, $\mathrm{H}_{2} \mathrm{O}_{2}$ production, and platelet activation, similar to that seen in SCD. These hemoglobin-induced mitochondrial effects are comparable to the effects of treating platelets with oligomycin, a complex $\mathrm{V}$ inhibitor. This suggests that cell-free hemoglobin causes mitochondrial dysfunction through inhibition of complex $\mathrm{V}$ with resultant ROS production and platelet activation (28). However, mitochondrial dysfunction in SCD may extend beyond platelet complex V. Treatment of sickle mice with Coenzyme Q10, a vital electron carrier in the mitochondrial respiratory chain, decreases expression of ROS in dorsal horn of the spinal cord, suggesting that the presence of mitochondrial oxidative stress may also contribute to chronic pain signaling in SCD (29).

In the presence of $\mathrm{H}_{2} \mathrm{O}_{2}$, ferrous hemoglobin oxidizes to ferryl hemoglobin plus a free radical, and then undergoes autoreduction to ferric methemoglobin. Mitochondria in any tissue may sustain oxidative damage as a result of ferryl hemoglobin and its radical. In cultured lung epithelial cells, exposure to ferryl $\mathrm{HbS}$ decreased mitochondrial maximal oxygen consumption rate and mitochondrial membrane potential. Incubation with haptoglobin prevented the decrease in mitochondrial oxygen consumption rate, implicating $\operatorname{HbS}(30)$.

\section{Non-heme sources of oxidative stress}

In addition to cell-free hemoglobin and hemin, NADPH oxidase, xanthine oxidase (XO), and uncoupled endothelial NO synthase (eNOS) generate oxygen free radicals that further promote endothelial dysfunction in SCD. Myeloperoxidase, released from activated 
neutrophils, also generates potent oxidants that can scavenge nitric oxide and impair endothelial function in $\operatorname{SCD}(31,32)$. Inhibition of myeloperoxidase in sickle mice dramatically improves endothelial-dependent vasodilation of aortas and reduced measures of oxidant stress and liver injury (32). Recent studies have confirmed increased levels of the oxidative stress markers myeloperoxidase (MPO), hydroxyl radical (HO•), lipid peroxidation and total thiols in SCD, while the antioxidants superoxide dismutase, glutathione and catalase were all reduced compared to controls $(31,33)$.

\section{Innate immunity and vaso-occlusion}

Innate immunity also plays a central role in modulating vascular and immune cell oxidative damage in SCD. Toll-like receptor 4 (TLR4) recognizes foreign pathogens and activates the innate immune system. In SCD, TLR4 likely engages a number of hemolysis- and inflammatory cell-derived ligands. High mobility group box protein 1 (HMGB1) is a DAMP that is released from activated immune cells or necrotic tissue. HMGB1 is increased in SCD plasma (34) and can synergize with products of hemolysis to activate toll-like receptors and RAGE $(35,36)$. Hemin induces TLR4 signaling in human lung microvascular endothelial cells, generating ROS, triggering apoptosis and endothelial barrier dysfunction (37). Hemin also activates NF- $\mathrm{BB}$ phospho-p65 in a TLR4-dependent signaling cascade, which can upregulate endothelial adhesion molecule expression in the setting of SCD (12). TLR4 signaling also activates protein kinase $\mathrm{C}$ and NADPH oxidase with subsequent generation of additional ROS and oxidant stress (12). Furthermore, endothelial heme-TLR4 signaling appears to result in complement deposition that is mediated in part by $\mathrm{P}$-selection expression (38).

There are strong inter-relationships between adhesion molecules, heme-mediated oxidative stress and the culmination of cell-cell interactions in sickle cell vaso-occlusion. Blockade or knock-out of endothelial P-selectin was protective against heme-induced acute lung injury in sickle mice (11). Furthermore, inhibition of neutrophil-platelet aggregates by blocking platelet P-selectin markedly improved lung vaso-occlusion in sickle mice, showing both the importance of platelet-neutrophil interactions in the vaso-occlusive process as well as the specific role of P-selectin (26). The complexity of neutrophil-platelet interactions is further evidenced by demonstrating that inhibiting neutrophil CD11b/CD18 (Mac-1) from binding to platelet glycoprotein Iba decreases neutrophil-platelet aggregations in SCD (27).

\section{Clinical Therapeutic agents}

Few medications are indicated for reducing the oxidative damage in SCD. It has also been challenging to determine the optimal biomarkers for measuring oxidant stress in SCD. Using $\mathrm{N}$-ethylmaleimide to block free thiols during sample processing, followed by highthroughput mass spectrometry, Fu et al found that cysteine, rather than glutathione, was the highest thiol-containing compound in sickle plasma (39). This may be a novel method to assess the level of oxidative stress and the biologic effect of antioxidant therapies in SCD. Hydroxyurea is the best-established disease-modifying pharmacotherapy for SCD. In addition to fetal hemoglobin induction, hydroxyurea also acts as an NO donor. Treatment 
with hydroxyurea increases RBC nitrite content, enhanced RBC deformability, and decreased reactive oxygen species levels in SCD (40).

Other therapeutic agents seek to protect RBC structural integrity from oxidative damage. The SCOT trial illustrated that omega-3 fatty acids have a protective effect on oxidative damage to sickle RBC membranes $\left(41^{*}\right)$. The study found increased total RBC membrane docosahexaenoic acid and eicosapentaenoic acid after just 4 weeks of therapy (41). GBT440 is an oral hemoglobin modifier that increases $\mathrm{Hb}$ oxygen affinity and reduces $\mathrm{HgS}$ polymerization in preclinical models, thereby preventing RBC sickling and improving RBC lifespan (42). Publication of a phase 1/2 clinical trial involving GBT440 (voxelotor) is forthcoming (43).

L-arginine, a substrate for NO production, has generated interest as a potential therapy to limit acute vaso-occlusive pain. Individuals with SCD patients treated with oral L-arginine plus hydroxyurea reported a reduction in pain episodes and had increased nitrite/nitrate levels compared to hydroxyurea alone (44).

Crizanlizumab is a monoclonal antibody that inhibits P-selectin. In the SUSTAIN trial, treatment with the higher dose of crizanlizumab reduced the annual rate of sickle cell-related acute painful episodes, but did not have an effect on the rate of other severe SCD complications such as sequestration or acute chest $\left(45^{*}\right)$.

Oral L-glutamine also reduced the median number of vaso-occlusive pain events over 48 weeks in individuals with SCD in a recent phase III trial (46). L-glutamine increases the level of reduced-NADs in sickle cell RBCs, which should relieve RBC oxidative stress. Lglutamine and others like it will undergo further study in the coming years to see what they add to SCD treatment (47).

\section{Conclusions}

SCD is characterized by a single-gene mutation with multi-system consequences (Figure 1). Mutated $\mathrm{HbS}$ leads to profound changes in RBC metabolism and physiology, endothelial signaling, sterile immune response, and the body's endogenous protections against hemolysis and hemolysis byproducts, all of which involve oxidative stress as either downstream or upstream mediators. Our knowledge of redox signaling in SCD is constantly growing as new signaling pathways are discovered. The therapeutic agents with the most promise for preventing oxidative damage in SCD exert their effects by decreasing ROS production or inhibiting pathways that respond to ROS (Figure 2). Improved understanding of oxidative stress in SCD will lead to targeted therapies that should improve outcomes for this underserved patient population.

\section{Acknowledgements:}

This work was supported by the National Institutes of Health grants HL128371 (C.A.H and K.A.P.), NS070711 (CAH), T32 HD071834 (D.N.D.), and support from the Vascular Medicine Institute, the Hemophilia Center of Western Pennsylvania, and the Institute for Transfusion Medicine. 


\section{Abbreviations:}

DAMP

HbS

IVIG

HMGB1

HO-1

$\mathrm{H}_{2} \mathrm{O}_{2}$

Keap1

MEK

MPO

NADH

NADPH

$\mathrm{NF}-\mathrm{xB}$

NO

NOS

Nrf2

RAGE

RBC

ROS

SCD

TLR4

VCAM-1

XO damage-associated molecular pattern

sickle hemoglobin

intravenous immune globulin

High mobility group box protein 1

heme oxygenase-1

hydrogen peroxide

Kelch-like ECH-associated protein 1

mitogen-activated protein kinase enzyme

myeloperoxidase

nicotinamide adenine dinucleotide (NAD) + hydrogen $(\mathrm{H})$

nicotinamide adenine dinucleotide phosphate

nuclear factor kappa-light-chain-enhancer of activated B cells

nitric oxide

nitric oxide synthase

Nuclear factor erythroid 2-related factor 2

receptor for advanced glycation end products

red blood cell

reactive oxygen species

Sickle cell disease

Toll-like receptor 4

vascular cell adhesion molecule-1

xanthine oxidase

\section{References and recommended reading:}

* of special interest

** of outstanding interest

1. Kato GJ, Piel FB, Reid CD, Gaston MH, Ohene-Frempong K, Krishnamurti L, Smith WR, Panepinto JA, Weatherall DJ, Costa FF, Vichinsky EP. Sickle cell disease. Nat Rev Dis Primers. 2018;4:18010. doi: 10.1038/nrdp.2018.10. PubMed PMID: 29542687. [PubMed: 29542687] 
2. Sundd P, Gladwin MT, Novelli EM. Pathophysiology of Sickle Cell Disease. Annu Rev Pathol. 2019;14:263-92. doi: 10.1146/annurev-pathmechdis-012418-012838. PubMed PMID: 30332562. [PubMed: 30332562]

3. Alayash AI. Oxidative pathways in the sickle cell and beyond. Blood Cells Mol Dis. 2018;70:78-86. doi: 10.1016/j.bcmd.2017.05.009. PubMed PMID: 28554826; PMCID: PMC5696113. [PubMed: 28554826]

4. Romana M, Connes P, Key NS. Microparticles in sickle cell disease. Clin Hemorheol Microcirc. 2018;68(2-3):319-29. doi: 10.3233/CH-189014. PubMed PMID: 29614639. [PubMed: 29614639]

5. Camus SM, Gausseres B, Bonnin P, Loufrani L, Grimaud L, Charue D, De Moraes JA, Renard JM, Tedgui A, Boulanger CM, Tharaux PL, Blanc-Brude OP. Erythrocyte microparticles can induce kidney vaso-occlusions in a murine model of sickle cell disease. Blood. 2012; 120(25): 5050-8. doi: 10.1182/blood-2012-02-413138. PubMed PMID: 22976952. [PubMed: 22976952]

6. Camus SM, De Moraes JA, Bonnin P, Abbyad P, Le Jeune S, Lionnet F, Loufrani L, Grimaud L, Lambry JC, Charue D, Kiger L, Renard JM, Larroque C, Le Clesiau H, Tedgui A, Bruneval P, Barja-Fidalgo C, Alexandrou A, Tharaux PL, Boulanger CM, Blanc-Brude OP. Circulating cell membrane microparticles transfer heme to endothelial cells and trigger vasoocclusions in sickle cell disease. Blood. 2015;125(24):3805-14. doi: 10.1182/blood-2014-07-589283. PubMed PMID: 25827830; PMCID: PMC4490297. [PubMed: 25827830]

*7. Jana S, Strader MB, Meng F, Hicks W, Kassa T, Tarandovskiy I, De Paoli S, Simak J, Heaven MR, Belcher JD, Vercellotti GM, Alayash AI. Hemoglobin oxidation-dependent reactions promote interactions with band 3 and oxidative changes in sickle cell-derived microparticles. JCI Insight. 2018;3(21). doi: 10.1172/jci.insight.120451. PubMed PMID: 30385713; PMCID:

PMC6238743.The authors used photometric and proteomic analyses to demonstrate increased levels of autoxidation of $\mathrm{HgS}$ within microparticles of Townes sickle cell mice, which was associated with modifications to band 3 and RBC membrane proteins, and with posttranslational modifications in $\beta$ Cys93, $\beta$ Lys96, and $\beta$ Lys145. Treatment with hydroxyurea decreased $\mathrm{Hb}$ related posttranslational modifications and levels of oxidized $\mathrm{Hb}$. This paper was the first to report a link between oxidative stress and the ubiquitin/proteasome system.

8. Kato GJ, Steinberg MH, Gladwin MT. Intravascular hemolysis and the pathophysiology of sickle cell disease. J Clin Invest. 2017;127(3):750-60. doi: 10.1172/JCI89741. PubMed PMID: 28248201; PMCID: PMC5330745. [PubMed: 28248201]

9. Voskou S, Aslan M, Fanis P, Phylactides M, Kleanthous M. Oxidative stress in beta-thalassaemia and sickle cell disease. Redox Biol. 2015;6:226-39. doi: 10.1016/j.redox.2015.07.018. PubMed PMID: 26285072; PMCID: PMC4543215. [PubMed: 26285072]

10. Potoka KP, Gladwin MT. Vasculopathy and pulmonary hypertension in sickle cell disease. Am J Physiol Lung Cell Mol Physiol. 2015;308(4):L314-24. doi: 10.1152/ajplung.00252.2014. PubMed PMID: 25398989; PMCID: PMC4329471. [PubMed: 25398989]

*11. Ghosh S, Flage B, Weidert F, Ofori-Acquah SF. P-selectin plays a role in haem-induced acute lung injury in sickle mice. Br J Haematol. 2019. doi: 10.1111/bjh.15807. PubMed PMID: 30809798.The SUSTAIN Trial demonstrated that anti-p-selectin antibody reduced the number of painful crises in sickle cell patients, but it did not affect the incidence of acute chest syndrome, possibly due to inadequate ACS events to analyze for statistical difference. To investigate the contribution of p-selectin to the development of acute chest in a murine sickle model, the authors of this study treated Townes SS mice with function-blocking monoclonal murine anti-P selectin antibody and then induced lung injury. Pretreatment of p-selectin monoclonal antibody was protective against lung injury in 5 of 6 pretreated mice, whereas all 6 untreated SS mice died. Furthermore, knockout mice negative for p-selectin on non-hematopoietic cells (endothelial cells) seemed to be protected against heme-induced lung injury compared to knockout mice negative for p-selectin on hematopoietic cells.

12. Belcher JD, Chen C, Nguyen J, Milbauer L, Abdulla F, Alayash AI, Smith A, Nath KA, Hebbel RP, Vercellotti GM. Heme triggers TLR4 signaling leading to endothelial cell activation and vasoocclusion in murine sickle cell disease. Blood. 2014;123(3):377-90. doi: 10.1182/ blood-2013-04-495887. PubMed PMID: 24277079; PMCID: PMC3894494. [PubMed: 24277079]

13. Vercellotti GM, Zhang P, Nguyen J, Abdulla F, Chen C, Nguyen P, Nowotny C, Steer CJ, Smith A, Belcher JD. Hepatic Overexpression of Hemopexin Inhibits Inflammation and Vascular Stasis in 
Murine Models of Sickle Cell Disease. Mol Med. 2016;22:437-51. doi: 10.2119/molmed. 2016.00063. PubMed PMID: 27451971; PMCID: PMC5082291. [PubMed: 27451971]

*14. Belcher JD, Chen C, Nguyen J, Abdulla F, Zhang P, Nguyen H, Nguyen P, Killeen T, Miescher SM, Brinkman N, Nath KA, Steer CJ, Vercellotti GM. Haptoglobin and hemopexin inhibit vasoocclusion and inflammation in murine sickle cell disease: Role of heme oxygenase-1 induction. PLoS One. 2018;13(4):e0196455. doi: 10.1371/journal.pone.0196455. PubMed PMID: 29694434; PMCID: PMC5919001. [PubMed: 29694434] The authors used Townes SS murine model to demonstrated that infusion of hapoglobin or hemopexin caused increased expression of HO-1 and decreased NF- $\kappa$ B phospho-p65 as well as vaso-occlusion for a period of up to 48 hours post-infusion. Infusion was also protective against hypoxia/reoxygenation and lipopolysaccharide-induced vaso-occlusion. The positive effects of haptoglobin or hemopexin infusion were reversed by inhibiting HO-1 activity with tin protoporphyrin, and were restored by carbon monoxide (a product of HO-1 catabolism of heme). The protective mechanism of carbon monoxide appears to mediate through inhibition of p-selectin and von Willebrand factor expression.

*15. Belcher JD, Gomperts E, Nguyen J, Chen C, Abdulla F, Kiser ZM, Gallo D, Levy H, Otterbein LE, Vercellotti GM. Oral carbon monoxide therapy in murine sickle cell disease: Beneficial effects on vaso-occlusion, inflammation and anemia. PLoS One. 2018; 13(10):e0205194. doi: 10.1371/journal.pone.0205194. PubMed PMID: 30308028; PMCID: PMC6181332 Minnesota. [PubMed: 30308028] The authors demonstrated that oral administration of carbon monoxide, which is more convenient for daily administration than inhaled or infused forms, can improve hemogobin levels, RBC counts, WBC counts, Nrf2 and HO-1 expression, and microvascular stasis in Townes SS mice.

16. Belcher JD, Chen C, Nguyen J, Zhang P, Abdulla F, Nguyen P, Killeen T, Xu P, O'Sullivan G, Nath KA, Vercellotti GM. Control of Oxidative Stress and Inflammation in Sickle Cell Disease with the Nrf2 Activator Dimethyl Fumarate. Antioxid Redox Signal. 2017;26(14):748-62. doi: 10.1089/ars. 2015.6571. PubMed PMID: 26914345; PMCID: PMC5421647. [PubMed: 26914345]

*17. Ghosh S, Hazra R, Ihunnah CA, Weidert F, Flage B, Ofori-Acquah SF. Augmented NRF2 activation protects adult sickle mice from lethal acute chest syndrome. Br J Haematol. 2018;182(2):271-5. doi: 10.1111/bjh.15401. PubMed PMID: 29923176. [PubMed: 29923176] The authors demonstrated that treatment with oral D3T (3H-1,2-dithiole-3-thione) three times per week for thress months, was protective against hemin-induced lung injury in Townes SS mice. Treatment with D3T elevated plasma levels of HO-1 and activates Nrf-2. The protective efffect of D3T was diminished in the presence of SnPPIX injection, which inhibited HO-1 activity.

18. Ghosh S, Ihunnah CA, Hazra R, Walker AL, Hansen JM, Archer DR, Owusu-Ansah AT, OforiAcquah SF. Nonhematopoietic Nrf2 dominantly impedes adult progression of sickle cell anemia in mice. JCI Insight. 2016;1(4). doi: 10.1172/jci.insight.81090. PubMed PMID: 27158670; PMCID: PMC4857015.

19. Keleku-Lukwete N, Suzuki M, Otsuki A, Tsuchida K, Katayama S, Hayashi M, Naganuma E, Moriguchi T, Tanabe O, Engel JD, Imaizumi M, Yamamoto M Amelioration of inflammation and tissue damage in sickle cell model mice by Nrf2 activation. Proc Natl Acad Sci U S A. 2015;112(39):12169-74. doi: 10.1073/pnas.1509158112. PubMed PMID: 26371321; PMCID: PMC4593117. [PubMed: 26371321]

20. Keleku-Lukwete N, Suzuki M, Yamamoto M. An Overview of the Advantages of KEAP1-NRF2 System Activation During Inflammatory Disease Treatment. Antioxid Redox Signal. 2018;29(17): 1746-55. doi: 10.1089/ars.2017.7358. PubMed PMID: 28899203. [PubMed: 28899203]

21. Krishnamoorthy S, Pace B, Gupta D, Sturtevant S, Li B, Makala L, Brittain J, Moore N, Vieira BF, Thullen T, Stone I, Li H, Hobbs WE, Light DR. Dimethyl fumarate increases fetal hemoglobin, provides heme detoxification, and corrects anemia in sickle cell disease. JCI Insight. 2017;2(20). doi: 10.1172/jci.insight.96409. PubMed PMID: 29046485; PMCID: PMC5846716.

*22. Li B, Zhu X, Ward CM, Starlard-Davenport A, Takezaki M, Berry A, Ward A, Wilder C, Neunert C, Kutlar A, Pace BS. MIR-144-mediated NRF2 gene silencing inhibits fetal hemoglobin expression in sickle cell disease. Exp Hematol. 2019;70:85-96 e5. doi: 10.1016/j.exphem. 2018.11.002. PubMed PMID: 30412705. [PubMed: 30412705] The authors performed a genomewide microRNA (miRNA) analysis for genes that induce $\mathrm{HgF}$ expression in patients with SCD. The found that patients with low $\mathrm{HgF}$ have higher expression of miR-144-3p (miR-144) and 
miR-144-5p. miR-144 can silence the NRF2 gene and prevent $\gamma$-globin transcription, but inhibiting miR-144 can reverse these effects. Treating KU812 cells with hemin induced NRF2 and $\mathrm{HbF}$, and miR-144 inhibited that effect. The authors used chromatin immunoprecipitation to illustrate that NRF2 bound to the $\gamma$-globin antioxidant response element, and a miR-144-like molecule was able to inhibit this interaction.

23. Owusu-Ansah A, Choi SH, Petrosiute A, Letterio JJ, Huang AY. Triterpenoid inducers of Nrf2 signaling as potential therapeutic agents in sickle cell disease: a review. Front Med. 2015;9(1):4656. doi: 10.1007/s11684-015-0375-1. PubMed PMID: 25511620. [PubMed: 25511620]

24. Zhu X, Oseghale AR, Nicole LH, Li B, Pace BS. Mechanisms of NRF2 activation to mediate fetal hemoglobin induction and protection against oxidative stress in sickle cell disease. Exp Biol Med (Maywood). 2019:1535370219825859. doi: 10.1177/1535370219825859. PubMed PMID: 30674214.

25. Zhu X, Xi C, Thomas B, Pace BS. Loss of NRF2 function exacerbates the pathophysiology of sickle cell disease in a transgenic mouse model. Blood. 2018;131(5):558-62. doi: 10.1182/ blood-2017-10-810531. PubMed PMID: 29255069; PMCID: PMC5794503. [PubMed: 29255069]

*26. Bennewitz MF, Jimenez MA, Vats R, Tutuncuoglu E, Jonassaint J, Kato GJ, Gladwin MT, Sundd P. Lung vaso-occlusion in sickle cell disease mediated by arteriolar neutrophil-platelet microemboli. JCI Insight. 2017;2(1):e89761. doi: 10.1172/jci.insight.89761. PubMed PMID: 28097236; PMCID: PMC5214368. [PubMed: 28097236] The authors used intravital microscopy to observe formation of microemboli in the lungs of transgenic humanized SCD mice after infusion of systemic lipopolysaccharide. The micoemboli were characterized by plateletneutrophil interactions. Human blood from SCD patients was examined in an in vitro microfluidic system and showed the same pattern of platelet-neutrophil interactions. Functionblocking antibody against p-selectin decreased the platelet-neutrophil aggregates in human samples and rescued formation of platelet-neutrophil aggregates in SCD mice.

27. Jimenez MA, Novelli E, Shaw GD, Sundd P. Glycoprotein Ibalpha inhibitor (CCP-224) prevents neutrophil-platelet aggregation in Sickle Cell Disease. Blood Adv. 2017;1(20):1712-6. doi: 10.1182/bloodadvances.2017006742. PubMed PMID: 28966995 ; PMCID: PMC5617353. [PubMed: 28966995]

28. Cardenes N, Corey C, Geary L, Jain S, Zharikov S, Barge S, Novelli EM, Shiva S. Platelet bioenergetic screen in sickle cell patients reveals mitochondrial complex V inhibition, which contributes to platelet activation. Blood. 2014;123(18):2864-72. doi: 10.1182/ blood-2013-09-529420. PubMed PMID: 24677541; PMCID: PMC4007612. [PubMed: 24677541]

29. Valverde Y, Benson B, Gupta M, Gupta K. Spinal glial activation and oxidative stress are alleviated by treatment with curcumin or coenzyme Q in sickle mice. Haematologica. 2016;101(2):e44-7. doi: 10.3324/haematol.2015.137489. PubMed PMID: 26546503; PMCID: PMC4938337. [PubMed: 26546503]

30. Kassa T, Jana S, Strader MB, Meng F, Jia Y, Wilson MT, Alayash AI. Sickle Cell Hemoglobin in the Ferryl State Promotes betaCys-93 Oxidation and Mitochondrial Dysfunction in Epithelial Lung Cells (E10). J Biol Chem. 2015;290(46):27939-58. doi: 10.1074/jbc.M115.651257. PubMed PMID: 26396189; PMCID: PMC4646035. [PubMed: 26396189]

31. Biswal S, Rizwan H, Pal S, Sabnam S, Parida P, Pal A. Oxidative stress, antioxidant capacity, biomolecule damage, and inflammation symptoms of sickle cell disease in children. Hematology. 2019;24(1):1-9. doi: 10.1080/10245332.2018.1498441. PubMed PMID: 30010491. [PubMed: 30010491]

32. Zhang H, Xu H, Weihrauch D, Jones DW, Jing X, Shi Y, Gourlay D, Oldham KT, Hillery CA, Pritchard KA Jr. Inhibition of myeloperoxidase decreases vascular oxidative stress and increases vasodilatation in sickle cell disease mice. J Lipid Res. 2013;54(11):3009-15. doi: 10.1194/ jlr.M038281. PubMed PMID: 23956444; PMCID: PMC3793605. [PubMed: 23956444]

33. Castilhos LG, de Oliveira JS, Adefegha SA, Magni LP, Doleski PH, Abdalla FH, de Andrade CM, Leal DBR. Increased oxidative stress alters nucleosides metabolite levels in sickle cell anemia. Redox Rep. 2017;22(6):451-9. doi: 10.1080/13510002.2017.1288973. PubMed PMID: 28209096. [PubMed: 28209096]

34. Xu H, Wandersee NJ, Guo Y, Jones DW, Holzhauer SL, Hanson MS, Machogu E, Brousseau DC, Hogg N, Densmore JC, Kaul S, Hillery CA, Pritchard KA Jr. Sickle cell disease increases high 
mobility group box 1: a novel mechanism of inflammation. Blood. 2014;124(26):3978-81. doi: 10.1182/blood-2014-04-560813. PubMed PMID: 25339362; PMCID: PMC4271182. [PubMed: 25339362]

35. Hreggvidsdottir HS, Lundberg AM, Aveberger AC, Klevenvall L, Andersson U, Harris HE. High mobility group box protein 1 (HMGB1)-partner molecule complexes enhance cytokine production by signaling through the partner molecule receptor. Mol Med. 2012;18:224-30. doi: 10.2119/ molmed.2011.00327. PubMed PMID: 22076468; PMCID: PMC3320135. [PubMed: 22076468]

36. Lin T, Sammy F, Yang H, Thundivalappil S, Hellman J, Tracey KJ, Warren HS. Identification of hemopexin as an anti-inflammatory factor that inhibits synergy of hemoglobin with HMGB1 in sterile and infectious inflammation. J Immunol. 2012;189(4):2017-22. doi: 10.4049/jimmunol. 1103623. PubMed PMID: 22772444; PMCID: PMC3426910. [PubMed: 22772444]

37. Singla S, Sysol JR, Dille B, Jones N, Chen J, Machado RF. Hemin Causes Lung Microvascular Endothelial Barrier Dysfunction by Necroptotic Cell Death. Am J Respir Cell Mol Biol. 2017;57(3):307-14. doi: 10.1165/rcmb.2016-0287OC. PubMed PMID: 28421813; PMCID: PMC5625223. [PubMed: 28421813]

38. Merle NS, Paule R, Leon J, Daugan M, Robe-Rybkine T, Poillerat V, Torset C, Fremeaux-Bacchi V, Dimitrov JD, Roumenina LT. P-selectin drives complement attack on endothelium during intravascular hemolysis in TLR-4/heme-dependent manner. Proc Natl Acad Sci U S A. 2019. doi: 10.1073/pnas.1814797116. PubMed PMID: 30850533.

39. Fu X, Cate SA, Dominguez M, Osborn W, Ozpolat T, Konkle BA, Chen J, Lopez JA. Cysteine Disulfides (Cys-ss-X) as Sensitive Plasma Biomarkers of Oxidative Stress. Sci Rep. 2019;9(1): 115. doi: 10.1038/s41598-018-35566-2. PubMed PMID: 30643157; PMCID: PMC6331564. [PubMed: 30643157]

40. Nader E, Grau M, Fort R, Collins B, Cannas G, Gauthier A, Walpurgis K, Martin C, Bloch W, Poutrel S, Hot A, Renoux C, Thevis M, Joly P, Romana M, Guillot N, Connes P. Hydroxyurea therapy modulates sickle cell anemia red blood cell physiology: Impact on RBC deformability, oxidative stress, nitrite levels and nitric oxide synthase signalling pathway. Nitric Oxide. 2018;81:28-35. doi: 10.1016/j.niox.2018.10.003. PubMed PMID: 30342855. [PubMed: 30342855]

*41. Daak AA, Dampier CD, Fuh B, Kanter J, Alvarez OA, Black LV, McNaull MA, Callaghan MU, George A, Neumayr L, Hilliard LM, Sancilio F, Rabinowicz AL, Heeney MM. Double-blind, randomized, multicenter phase 2 study of SC411 in children with sickle cell disease (SCOT trial). Blood Adv. 2018;2(15):1969-79. doi: 10.1182/bloodadvances.2018021444. PubMed PMID: 30097463; PMCID: PMC6093734. [PubMed: 30097463] The SCOT Trial was a pediatric phase II randomized double-blind dose finding study to examine SC411, a novel DHA ethyl ester formulation which enhances DHA bioavailability in sickle cell disease. 67 pediatric patients were randomized to 4 treatment groups consisteing of any of different doses of SC411 or placebo. At time point 4 weeks after treatment, there was measurable increase in the primary endpoints of blood cell membrane DHA and eicosapentaenoic acid. At time point 8 weeks of treatment, there was decrease in the secondary endpoints of d-dimer and E-selectin expression in the mid-dose group of SC411, and an increase in Hg in the low-dose SC411 group. There was no reduction in the number of reported clinical sickle cell related crises. Adverse events attributed to SC411 were minimal.

42. Oksenberg D, Dufu K, Patel MP, Chuang C, Li Z, Xu Q, Silva-Garcia A, Zhou C, Hutchaleelaha A, Patskovska L, Patskovsky Y, Almo SC, Sinha U, Metcalf BW, Archer DR. GBT440 increases haemoglobin oxygen affinity, reduces sickling and prolongs RBC half-life in a murine model of sickle cell disease. Br J Haematol. 2016;175(1):141-53. doi: 10.1111/bjh.14214. PubMed PMID: 27378309. [PubMed: 27378309]

43. Howard J, Hemmaway CJ, Telfer P, Layton DM, Porter J, Awogbade M, Mant T, Gretler DD, Dufu K, Hutchaleelaha A, Patel M, Siu V, Dixon S, Landsman N, Tonda M, Lehrer-Graiwer J. A phase $1 / 2$ ascending dose study and open-label extension study of voxelotor in patients with sickle cell disease. Blood. 2019. doi: 10.1182/blood-2018-08-868893. PubMed PMID: 30655275.

44. Eleuterio RMN, Nascimento FO, Araujo TG, Castro MF, Filho TPA, Filho PAM, Eleuterio J Jr., Elias DBD, Lemes RPG Double-Blind Clinical Trial of Arginine Supplementation in the Treatment of Adult Patients with Sickle Cell Anaemia. Adv Hematol. 2019;2019:4397150. doi: 10.1155/2019/4397150. PubMed PMID: 30853991; PMCID: PMC6378076. [PubMed: 30853991] 
*45. Ataga KI, Kutlar A, Kanter J, Liles D, Cancado R, Friedrisch J, Guthrie TH, Knight-Madden J, Alvarez OA, Gordeuk VR, Gualandro S, Colella MP, Smith WR, Rollins SA, Stocker JW, Rother RP. Crizanlizumab for the Prevention of Pain Crises in Sickle Cell Disease. N Engl J Med. 2017;376(5):429-39. doi: 10.1056/NEJMoa1611770. PubMed PMID: 27959701; PMCID: PMC5481200. [PubMed: 27959701] This study, the SUSTAIN study, was a double blind randomized phase II trial which assigned 198 sickle cell patients to receive intravenous low-dose crizanlizumab, high-dose crizanlizumab, or placebo, 14 times over a period of 52 weeks. The primary endpoint was the annual rate of sickle cell-related pain crises in the high dose crizanlizumab group vs placebo. Secondary endpoints included number of hospitalization days; time to first and second crises; annual rates of crises not including acute chest syndrome, sequestration, or priapism; and rates of acute chest syndrome. The high dose crizanlizumab group experienced fewer crises and a longer time to first and second crisis, as well as a lower rate of "uncomplicated" crises. Rates of severe crisis (acute chest syndrome, sequestrations, priapism) were not different among the groups, but this may be attributable to the overall infrequency of these events in all groups throughout the trial. There was no difference in markers of hemolysis for the treatment groups vs. placebo. Adverse events in both the low- and high-dose treatment groups included arthralgia, diarrhea, pruritus, vomiting, and chest pain, in about $10 \%$ of participants, which was more than in the placebo group.

46. Niihara Y, Miller ST, Kanter J, Lanzkron S, Smith WR, Hsu LL, Gordeuk VR, Viswanathan K, Sarnaik S, Osunkwo I, Guillaume E, Sadanandan S, Sieger L, Lasky JL, Panosyan EH, Blake OA, New TN, Bellevue R, Tran LT, Razon RL, Stark CW, Neumayr LD, Vichinsky EP, Investigators of the Phase 3 Trial of 1-Glutamine in Sickle Cell D. A Phase 3 Trial of 1-Glutamine in Sickle Cell Disease. N Engl J Med. 2018;379(3):226-35. doi: 10.1056/NEJMoa1715971. PubMed PMID: 30021096. [PubMed: 30021096]

47. Quinn CT. 1-Glutamine for sickle cell anemia: more questions than answers. Blood. 2018;132(7): 689-93. doi: 10.1182/blood-2018-03-834440. PubMed PMID: 29895661. [PubMed: 29895661] 


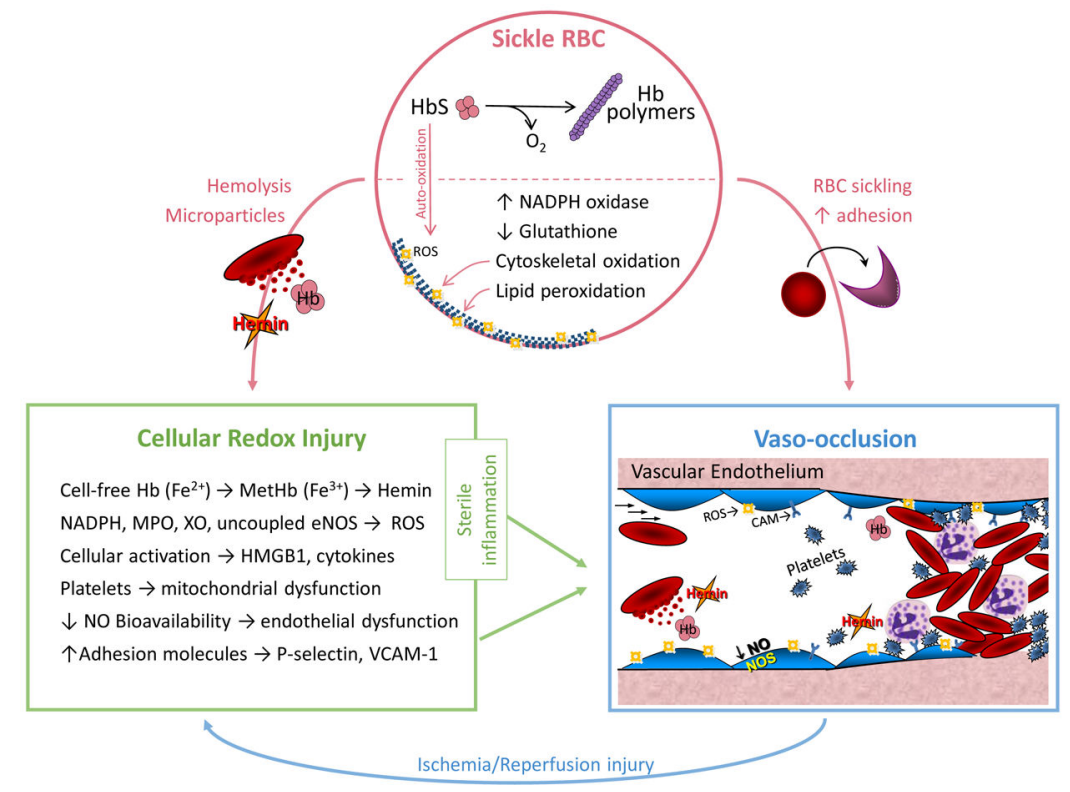

Figure 1: Redox Pathophysiology of Sickle Cell Disease (SCD).

Sickle $R B C$. A single point mutation in the beta globin $(H B B)$ gene results in sickle hemoglobin ( $\mathrm{HbS}$ ), which reversibly polymerizes upon deoxygenation leading to red blood cell (RBC) sickling. Auto-oxidation of unstable $\mathrm{HbS}$ forms reactive oxygen species (ROS), upregulation of nicotinamide adenine dinucleotide phosphate (NADPH) oxidase and depletion of glutathione, further contributing to RBC oxidative stress, cytoskeletal oxidation and lipid membrane peroxidation. Fragile sickle RBCs are prone to lysis, releasing intracellular components and microparticles into the circulation. Cellular Redox Injury. Cellfree $\mathrm{Hb}\left(\mathrm{Fe}^{2+}\right)$ can be oxidized to MetHb $\left(\mathrm{Fe}^{3+}\right)$ by scavenging nitric oxide (NO) or reacting with $\mathrm{H}_{2} \mathrm{O}_{2}$ (Fenton reaction); once oxidized, hemin is readily released from MetHb. Increased circulating or cellular NADPH oxidase, myeloperoxidase (MPO), xanthine oxidase (XO) and uncoupled endothelial nitric oxide synthase (eNOS) also generate ROS in $\mathrm{SCD}$. Immune cell and platelet activation release high mobility group box protein 1 (HMGB1) and cytokines. Hemin, ROS, HMGB1 and cytokines all promote sterile inflammation, endothelial dysfunction and increased expression of adhesion molecules, such as P-selectin and vascular cell adhesion molecule-1 (VCAM-1). Vaso-occlusion: RBC sickling and increased adhesion between the neutrophils, platelets, sickle RBCs and the vascular endothelium lead to stasis of blood flow, known as vaso-occlusion in SCD. Repeated episodes of vaso-occlusion produce ischemia/reperfusion injury that further contributes to cellular redox injury and sterile inflammation. Used with permission from Cheryl A. Hillery. 


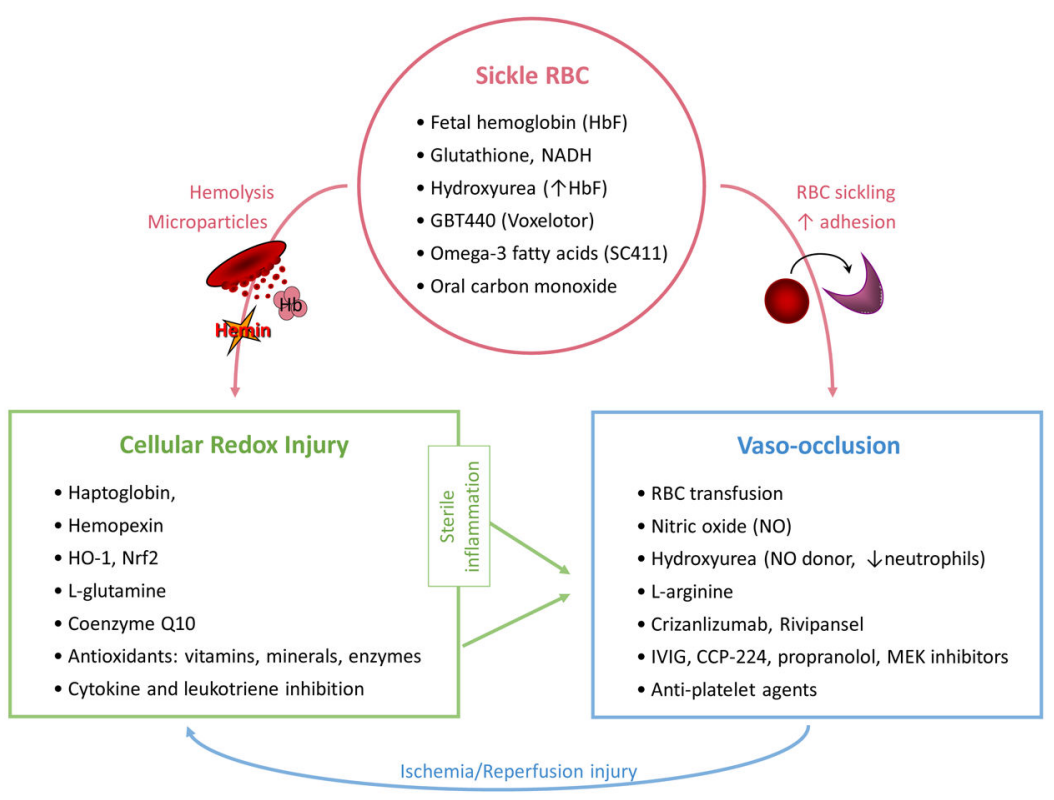

Figure 2: Protective Mechanisms and Therapeutic Targets.

Endogenous molecules and exogenous drugs target different pathways to protect against redox injury in SCD. Sickle $R B C$ : Fetal hemoglobin $(\mathrm{HbF})$, glutathione, NADH,

hydroxyurea, GBT440 (voxelotor), omega-3-fatty acids (SC411) and oral carbon monoxide help prevent RBC injury by reducing $\mathrm{HbS}$ polymerization or by stabilizing the RBC membrane. Cellular Redox Injury. Haptoglobin, hemopexin, heme oxygenase-1 (HO-1), Nuclear factor erythroid 2-related factor 2 (Nrf2), L-glutamine, coenzyme Q10, a wide variety of antioxidants and inhibition of cytokines or leukotrienes are both natural protective mechanisms against redox injury and potential therapeutic strategies to reduce redox stress in SCD. Vaso-occlusion: RBC transfusion, nitric oxide (NO), hydroxyurea, L-arginine, crizanlizumab (P-selectin inhibitor), rivipansel (pan-selection inhibitor), intravenous immune globulin (IVIG), CCP-224 (glycoprotein Iba inhibitor), mitogen-activated protein kinase enzyme (MEK) inhibitors and anti-platelet agents are aimed at improving endothelial dysfunction and preventing cell-cell interactions, which play vital roles in vaso-occlusion. Only hydroxyurea and l-glutamine are FDA approved for the treatment of SCD. Used with permission from Cheryl A. Hillery. 


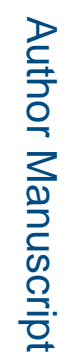

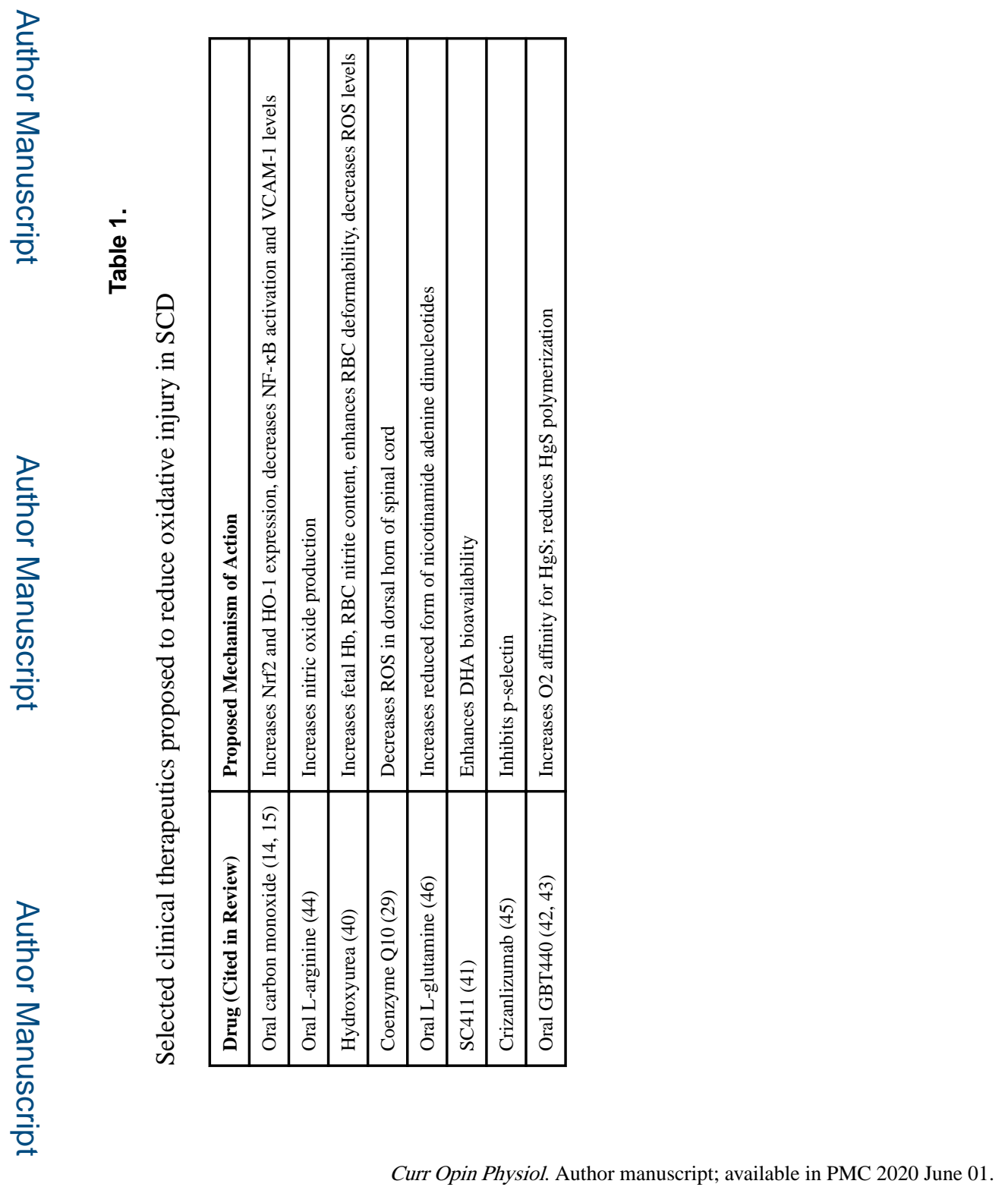

